\title{
Chemical analytical methods for diagnosing three narcotic substances in opiate neural drugs
}

\author{
Adil A. Al-Fregi', Hussein H. Hussein ${ }^{2}$, Maan Al-Nuaim ${ }^{3}$ \\ ${ }^{1}$ Department of Chemistry, College of Science, University of Basrah, Basrah, Iraq, ${ }^{2}$ Department Pharmaceutical \\ Chemistry, College of Pharmacy, University of Basrah, Basrah, Iraq, ${ }^{3}$ Department Pharmaceutical Chemistry, \\ College of Pharmacy, University of Basrah, Iraq
}

\begin{abstract}
Introduction: The study included the development of a new high sensitivity method in the measurement of different pharmaceutical drug samples. The high-performance liquid chromatography (HPLC)-UV detector was tested, and three narcotic components were tested in pharmaceutical tablets. The analysis used in the detection and qualitative evaluation of narcotic substances includes three phases of internationally approved measurements to confirm the validity of the results obtained. Materials and Methods: The first step is to use local color detectors under the light microscope and use a detector $\left(20 \% \mathrm{HC}_{2} \mathrm{H}_{3} \mathrm{O}_{2}\right.$ and platinum chloride). This reagent reacts with the drug molecule and gives a specific color to this molecule that can be detected clearly under the optical microscope with a magnification of 200 megapixels

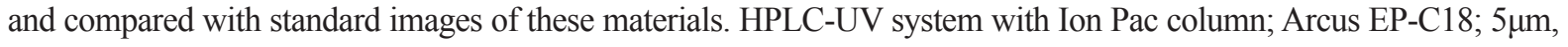
$4.6 \times 250 \mathrm{~mm}$, with a flow rate of $1.2 \mathrm{ml} / \mathrm{min}$ at $25^{\circ} \mathrm{C}$ and maximum wavelength $275 \mathrm{~nm}$ where the number of samples is isolated and determination of type the narcotics in mixture. The third step in the diagnosis involved the use of the mass spectrometry (MS) of each material in the mixture using the gas chromatography (GC)-MS (MSDCHEM $\backslash 1 \backslash$ METHODS\MUAFAQ.M) to identify negative $\mathrm{M} / \mathrm{Z}$ ions at the range temperature $\left(70-375^{\circ} \mathrm{C}\right)$. Results: The spots color tests revealed the nature of the drug compounds in the pharmaceutical product. The images and the morphology were compared with pictures of similar standard models for the purpose of inference. The HPLC revealed that the number of peaks in this method is three peaks that clearly indicate the number of substances in the mixture. The third detection was carried out using GC. The separation of the GC was done to identify the molecular masses of each component in the sample. Conclusion: The results of the microscopic analysis showed the appearance of three forms of narcotic compounds under study that closely resembles the standard images of the compounds themselves. Analysis of HPLC showed three clear peaks of compounds in this combination. Analysis of GC-Ms showed the molecular clusters of three compounds in pharmaceutical drug tablets. All the results of the analysis obtained indicate the accuracy and sensitivity of the method used in the analysis and measurement.
\end{abstract}

Key words: Codeine, morphine, pharmaceutical opium derivatives, thebenine

\section{Highlights}

- Diagnosis of three opium derivatives in a pharmaceutical product.

- Color changes of colored spots under the microscope are indicative of initial and fundamental detection.

- Qualitative detection using high-performance liquid chromatography technique for three components of opium derivatives in the pharmaceutical formulation.

- GC-Mass technique is important in determining the molecular mass of three opium derivatives.

- Retrospective values were calculated for a number of obtained results with a range of $90-97 \%$.

\section{INTRODUCTION}

$\mathrm{O}$ pium in Latin: Opium is a narcotic substance extracted from the poppy plant and used for the manufacture of heroin. According to United Nations sources, Afghanistan is currently the primary source of opium. ${ }^{[1]}$

Address for correspondence:

Hussein H. Hussein, Department Pharmaceutical Chemistry, College of Pharmacy, University of Basrah, Basrah, Iraq. Mobile: +9647702683703. E-mail: hsennaserh@yahoo.com

Received: 08-10-2018

Revised: 07-11-2018

Accepted: 19-11-2018 
In 1803, the French pharmacist Jean-François Durosne discovered the opium. Another French chemist, Arman Suguin, confirmed the discovery in 1804 of opium in the form of crystals. His salts were obtained only in 1817 by German pharmacist Friedrich Sturner. The opium contains two main groups of alkaloids: Phenanthrene, which include morphine, codeine, and thebaine, the main constituents of narcotic. As well as isocenolins such as poppy and nosocapine, which have no significant effect on the central nervous system and are not subject to criminal law as dangerous narcotic substances. Morphine is the most common and most important alkaloids in opium, consisting of $10-16 \%$ of the total opium components. It is responsible for most adverse effects such as lung edema, lung edema, dyspnea, coma, heart failure, and respiratory arrest. $250 \mathrm{mg}$ quantities were found in about $2 \mathrm{~g}$ of opium. Morphine binds and activates the opioid receptors in the brain, spinal cord, stomach, and intestine. Regular use can lead to dependence or physical habituation. ${ }^{[2-5]}$

Three opioid receptors such as alpha, beta, and gamma are receptors for opioid ORL1. These opioids control pain, and these opioids are controlled through reward and addiction to sensory cells in the brain. Opioid receptors are more abundant in the brain and are found in the cells of the nervous system, respiratory tract, and spinal cord. Fun activities such as laughter and abnormal joy are caused by endorphins, dynorphin, and enkephalins, which are produced by nerve cells in the brain that activates the opioid receptors and thus improves their metabolism. Opioid receptors can also be activated by external compounds such as narcotic analgesics that work on alpha receptors in the brain and are very effective in relieving pain, but unfortunately, the activation of addiction reward routes and the need to use excessive and increase the doses taken over time. ${ }^{[6,7]}$ There are a number of chemical and biological medical properties of the three narcotic components under research that needs to be mentioned to benefit the research procedure as follows:

1. Morphine and molecular formula: $\mathrm{C}_{17} \mathrm{H}_{19} \mathrm{NO}_{3}$ and its molecular mass $285.34 \mathrm{~g} / \mathrm{mol}$ and melting point: $255^{\circ} \mathrm{C}$. It is soluble in water. Scientific UPIC name:

(4R,4aR, 7S, 7aR, 12bS)-3-methyl-2,4,4a, 7, 7a, 13hexahydro-1H-4,12-methanobenzofuro isoquinoline-diol) Figure 1a.

$[3,2-\mathrm{e}]$

Morphine is marketed under many brand names, a powerful pain reliever of the opiate class. Morphine works directly on the central nervous system to reduce pain. It can be used for both acute pain and chronic pain. Morphine is also used to relieve pain caused by blockage of the heart muscle as well as during childbirth. It can be administered orally, intramuscularly, subcutaneously, intravenously, into the space around the spinal cord, or through the rectum. When intravenous morphine is given, the maximum effect is after $20 \mathrm{~min}$, and when taken orally, the maximum effect is $60 \mathrm{~min}$ and lasts between 3 and $7 \mathrm{~h}$. There are also compositions and morphine is the key element of the partial synthesis of its derivatives: Codeine, Cocaethylene, and diamorphine. Its legal production is limited to medical needs. ${ }^{[8,9]}$

2. Codeine: Codeine or methylmorphine is an opioid used as a pain reliever, cough medicine, and anti-diarrhea drug. Codeine or 3-methylmorphine, naturally present in the form of morphine, contains a methyl group, an opioid used as a painkiller, cough medicine, and antidiarrhea. The molecular formula has $\mathrm{C}_{18} \mathrm{H}_{21} \mathrm{NO}_{3}$, and its molecular mass is $299.14 \mathrm{~g} / \mathrm{mol}$, and the melting point is $154^{\circ} \mathrm{C}$ and is soluble in water ${ }^{[10,11]}$ Its scientific name is $\quad[(5 \alpha, 6 \alpha)-7,8$-didehydro-4,5-epoxy- 3-methoxy-17methylmorphinan-6-ol] Figure $1 \mathrm{~b}$.

Codeine or methylmorphine is an opioid formulation used as a pain reliever, cough medicine, and anti-diarrhea medication. Codeine or 3-methylmorphine is naturally present in the form of morphine containing the methyl group, an opioid preparation used as a pain reliever, cough medicine, and anti-diarrhea medication. Codeine is commonly sold in the United States in the form of salt (codeine phosphate or codeine sulfate); codex hydrochlorate is the most common form around the world and can also be found in the form of citrate, iodine hydrate, bromide hydrate, and many other salts. Codeine is the second most alkaloid (alkaloids) ratio in opium; the ratio may reach 3\%. Although codeine can be obtained from natural sources, the first source of code used in the pharmaceutical industry is a semi-synthetic compound (made from morphine by methanol). Codeine is the primary compound of weak and intermediate elephants (tramadol, dextropropoxifeno, dihydrocodeine, hydrocodone, and oxycodone). In 2013, approximately $361,000 \mathrm{~kg}$ was produced, and $249,000 \mathrm{~kg}$ of codeine was used. Codeine is one of the most frequently used opiates. The codes are listed in the World Health Organization's list of essential drugs, which include the most important drugs needed in the basic treatment system. ${ }^{[12,13]}$

3 Thebenine that shows in Figures $1 \mathrm{c}$ and $2 \mathrm{c}$ has a molecular formula: $\mathrm{C}_{19} \mathrm{H}_{21} \mathrm{NO}_{3}$ and molecular mass $327.2 \mathrm{~g} / \mathrm{mol}$, IUPAC name [codeine methyl enol ether] or [Para morphine]. It is a toxic chemical compound that is controlled under international law as a narcotic substance and one of the most toxic substance and has an effect on the killing of neural brain cells directly ${ }^{[14]}$ Figure 1c.

The most important application methods of chromatography (ion chromatography-UV), gas chromatography (GC)-mass and spot color tests are determination of three compounds in the mixture of narcotic substances in pharmaceutical materials. The three active materials found in the form tablets at approximately rate $25 \% \mathrm{~W} / \mathrm{W}$ from sample weight. Chromatography technique with UV detection at $275 \mathrm{~nm}$ wavelength with Ion Pac Arcus EP-C18, it is the best technique to detect the narcotic substances. ${ }^{[15,16]}$

The gas mass spectrometer was used, and the three compounds were identified in optimal conditions with the 


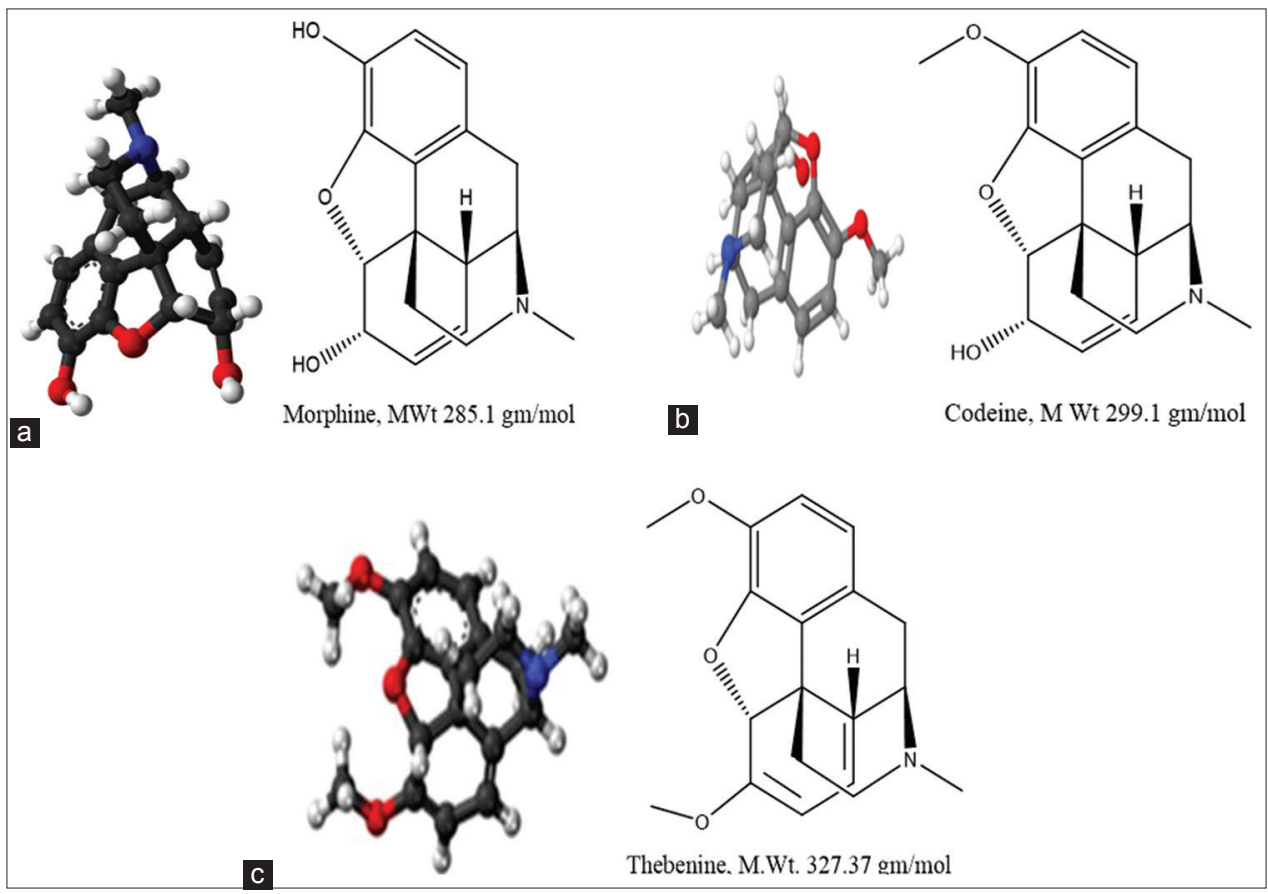

Figure 1: (a) The structural formula of morphine, (b) the structural formula of codeine, and (c) the structural formula of thebenine

help of the library reference in the GC-mass. The second test is the detection of colored spots under the microscope, which plays an important role in detecting the number of components of the mixture of drugs, the presence of color reagents for each type of drugs make the application of these methods more successful in determining the type and class of substances. ${ }^{[17]}$

GC-mass technique is the most largely applied since it provides high sensitivity, requires short chromatography run times, and has the potential to reduce extensive sample preparation because it does not need derivatization. To obtain high throughput screening, methods such as thinlayer chromatography (TLC), high-performance liquid chromatography (HPLC), and electrokinetic can be applied. Yet, GC-mass has been still widely used to maintain such type of screening when the results should be confirmed. Due to GC-Mass advantages such as its lower cost and the absence of a derivatization step before analysis, it has been turned to be the best method of tests. On the other hand, HPLC method is more easier to determine the class of narcotics substances than other ones and has begun to spread widely as an alternative technique to achieve analysis purposes, so as to its very good advantages. Moreover, it has become more common even though GC-Mass technique provides more sensitivity and is less susceptible to matrix interferences, so both HPLC techniques and GC-Mass appear to be as a useful method for quantification and routine analysis. Both GC-Mass and HPLC-UV require the same extensive cleaning of the model, and the analysis process requires a derived configuration step for the sample to be analyzed. The study of the two techniques shortens the time spent cleaning the sample to use these devices again. ${ }^{[18,19]}$

\section{The Aim of Study}

The aim of the study was to find an effective, fast, and highly sensitive way to a qualitative analysis of neural opiate drugs.

\section{Equipment}

1. Optical microscope equipped with camera (120-megapixel magnifying glass)

2. Ion chromatography (IC)-UV system including.

- $\quad$ LKB Bump 2150-HPLC, Bromma

- IonPac column Arcus EP-C18; $5 \mu \mathrm{m}, 4.5 \times 250 \mathrm{~mm}$ (P/N 11051194 L)

- Metrohm electric injection valve with $100 \mu \mathrm{L}$ loop inject in the system before flow cell quartz

- A PD 303 UV detector

- $\quad$ Equipped with $18 \mu \mathrm{l}$ flow cell (Helma. UK).

3. GC-mass system (MSDCHEM $\backslash 1 \backslash$ METHODS $\backslash$ MUAFAQ.M) to the determination of $\mathrm{M} / \mathrm{Z}$ negative ions.

4. Personal computer supplied with modifies software programs/CVI programs UV.

5. $\mathrm{pH}$ meter (Hana-Italy).

\section{MATERIALS AND METHODS}

All solvents and reagents were of analytical grade unless indicated otherwise, and all experiments were performed 
with deionized water $(18.2 \Omega-\mathrm{cm})$ resistivity at $25^{\circ} \mathrm{C} .{ }^{[20]}$

\section{Reagents and Standards}

- Dichloride methane (DCM) BDH Chemical Ltd.

- $20 \% \mathrm{HC}_{2} \mathrm{H}_{3} \mathrm{O}_{2}$ and platinic chloride $\left(\mathrm{PtCl}_{2}\right)$

- Ethanol and methanol, BDH Chemical Ltd.

- Acetonitrile, BDH Chemical Ltd.

- Helium gas (very purity).

\section{Working Methods}

\section{Qualitative estimation of narcotic substances in the studied samples}

1. $5 \mathrm{~g}$ of the sample washed with deionized water were taken well, and the default color test was performed with $20 \% \mathrm{HC}_{2} \mathrm{H}_{3} \mathrm{O}_{2}$ and $\mathrm{PtCl}_{2}$ as a reagent. Sampling is under the microscope and compared with the standard shapes previously measured from the material. ${ }^{[21]}$

2. $5 \mathrm{~g}$ of sample were taken to be tested. Dissolve the sample in $100 \mathrm{ml}$ (1:1:1) ethanol:ethanol:acetonitrile. The sample undergoes the HPLC test in standard conditions to accurately determine the number of substances in the sample. TLC technology can be eliminated inaccurate and avoid any possible interference to prove the number of materials in the mix. HPLC results have clearly demonstrated a number of drugs in the sample components through a number of peaks in chromatogram. ${ }^{[16]}$

3. The sample taken for testing was thoroughly washed with deionized water and then weighed $5 \mathrm{~g}$ from sample that dissolved well in a mixture of DCM solution, filtering the sample with filter paper type Millipore USA $(0.45 \mu \mathrm{m})$, and the filtration liquid was taken to the testing process in the GC-mass instrument. ${ }^{[22]}$

\section{RESULTS AND DISCUSSION}

\section{Analyze Method by Presumptive Color Test}

Color tests simply involve adding a reagent or reagents to the unknown material and observing a color change and the change of color may indicate the presence of a drug or a class of opium. The chemical mechanism involves the adding of reagent to the narcotic molecules that shift the optical absorption into the visible by the auxochrome group. ${ }^{[23]}$

Since more than one compound can produce the same results, color tests are not specific tests and cannot determine the existence of a compound conclusively. However, they are a good initial testing tool that is easy to implement, and color tests are often used by law enforcement agencies as a preliminary test when examining a suspected drug.
Figure 2a-c shows the narcotic substances and their images under the light microscope. ${ }^{[24]}$

\section{Analyze Method by HPLC-UV System (Qualitative Measurement)}

Chromatograms of a narcotic substance samples, as well as comparison of peaks and retention time, allow the identification of some narcotics, recoveries for standard sample ranged from $90 \%$ to $97 \%$ suggesting that the analysis method is accurate. All results were obtained by optimum conditions that are shown in Table 1.

For the purpose of determining the number of core components in the sample, HPLC-UV was used at a maximum wavelength of $275 \mathrm{~nm}$ and a flow rate of $1 \mathrm{~m} / \mathrm{min}$ and a volume of sample $100 \mu \mathrm{m}$ at $25^{\circ} \mathrm{C}$. Separation column using C18 using rinse gradient with methanol:ethanol:acetonitrile (1:1:1) V/V/V. Advanced HPLC technology helped identify three peaks representing the number of opium components in the pharmaceutical product, as shown in Figure 3.

\section{Analyze Method by GC-mass Spectrum}

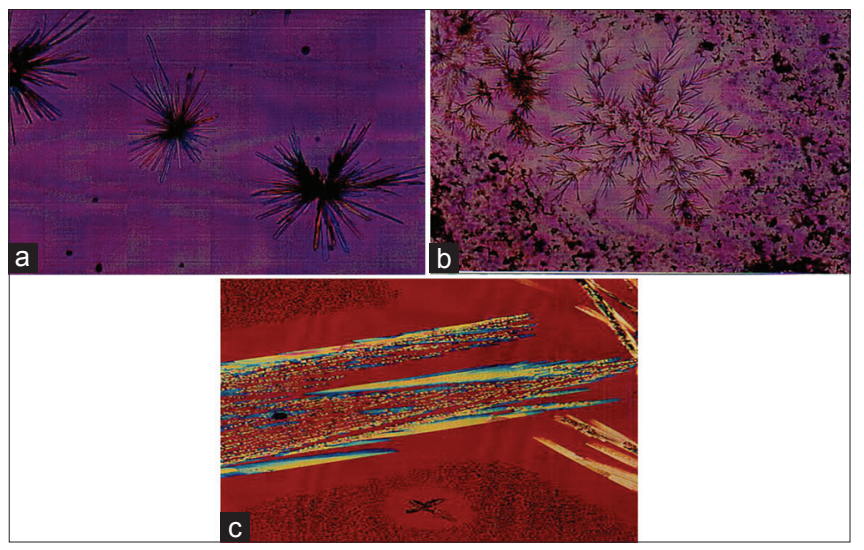

Figure 2: For three narcotics substances images under optical microscope. (a) Morphine, (b) codeine, and (c) thebenine

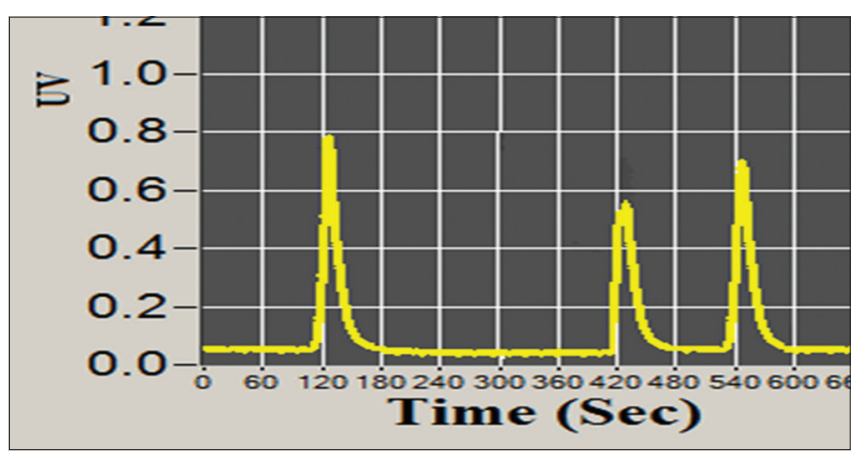

Figure 3: High-performance liquid chromatography peak's for three narcotic substances 
The compounds were study through GC-mass spectrometry (MS) [Table 2] to create the molecular ion for each compound and it was found equal to formula weight minus one as shown in Figures 3, 4, 4a, 4b and 4c which confirm the molecular weight of narcotic structures of this study gave a good indication for isolation and identification of morphine, codeine, and thebeinine ${ }^{[25]}$
The study demonstrates that with the proper use of all narcotics can be analyzed by GC-Mas. The reaction conditions may have to response of the morphine, codeine, and thebenine that are shown in Figures $4 \mathrm{a}, 4 \mathrm{~b}$ and $4 \mathrm{c}$. the molecular ion fragments of narcotic substance were characterized by mass spectra. To reduce the overall GC analysis time of these compound, a short, narrow bore column such as the $30 \mathrm{~m} \times 0.250 \mu \mathrm{m}$ I.D. $\times 0.25 \mu \mathrm{m}$,

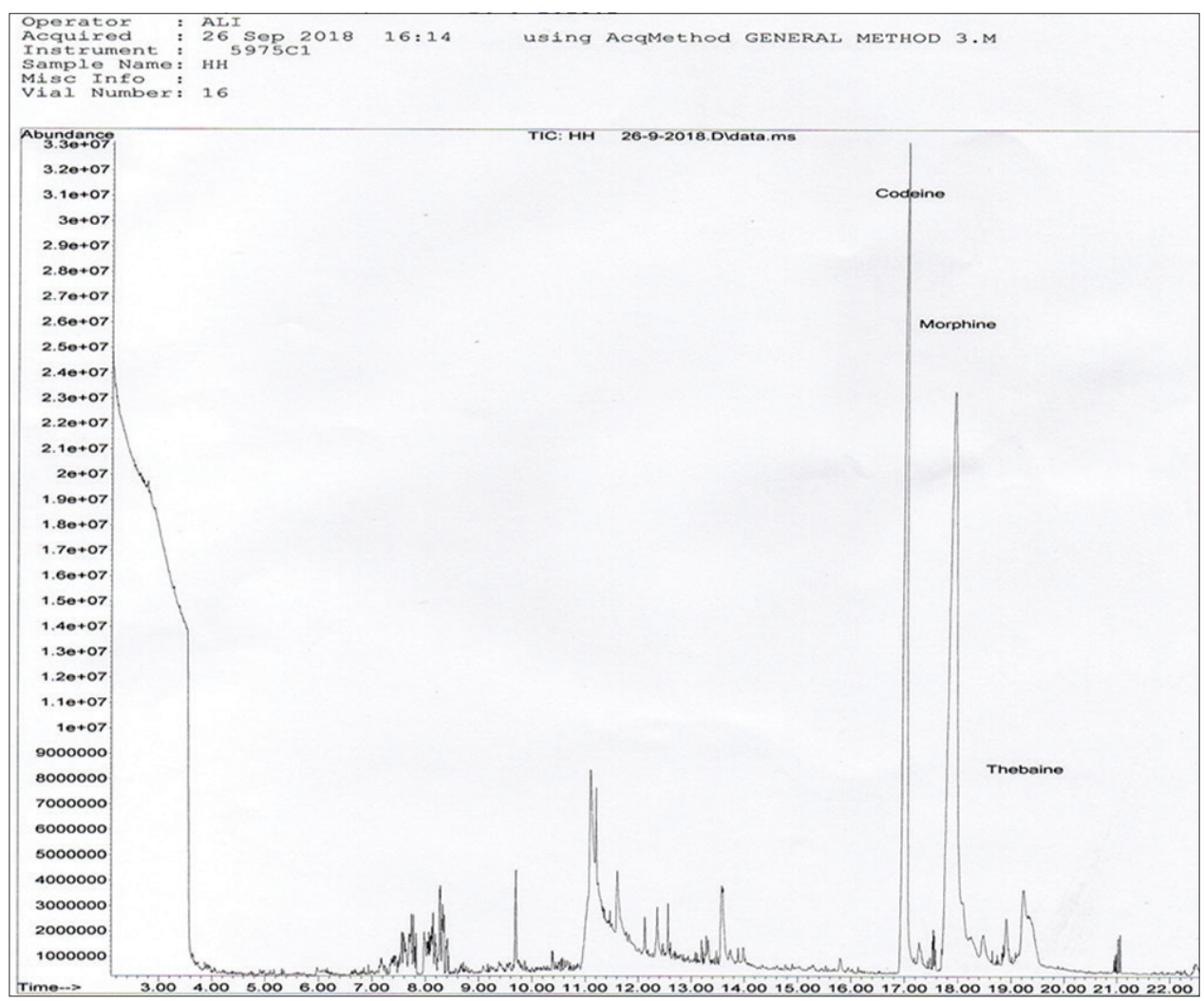

Figure 4: Gas chromatography-mass spectrum for three narcotics structures

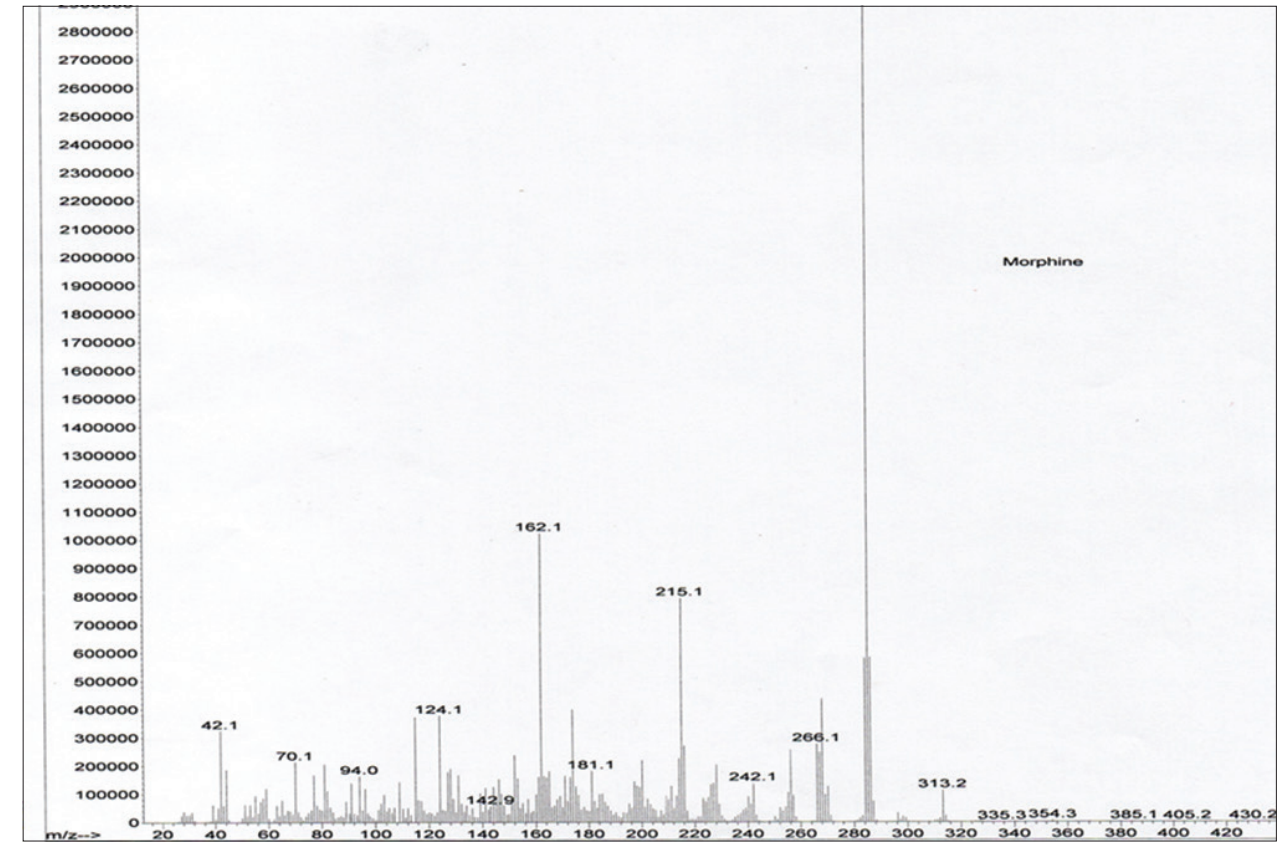

Figure 4a: Mass spectrum for morphine 
SS., Inlet He is recommended. ${ }^{[26]}$ Figures $4 \mathrm{a}-4 \mathrm{c}$ show the mass spectra degradation of narcotics substances morphine, codeine and thebenine, respectively and Schemes 1-3 show the mechanism of degradation of morphine, codeine and thebenine, respectively. The optimum conditions for mass spectra are summarized in Table 2.

\section{Discussion}

Three cases in which the results obtained can be discussed as follows:

\section{By presumptive color test}

The color tests are not fully dependable because there are more than one compound can give the same results. Moreover, such tests cannot conclusively identify the presence of a compound; however, they are practically considered a good

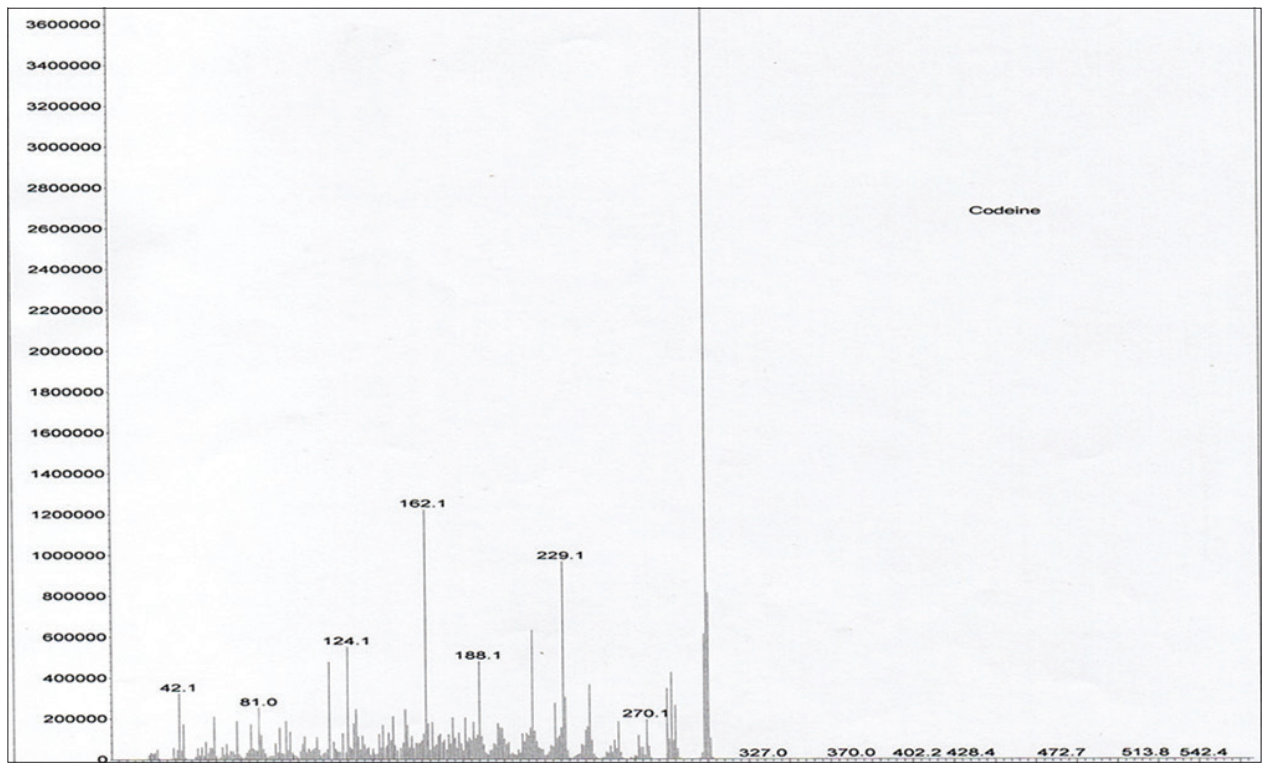

Figure 4b: Mass spectrum for codeine

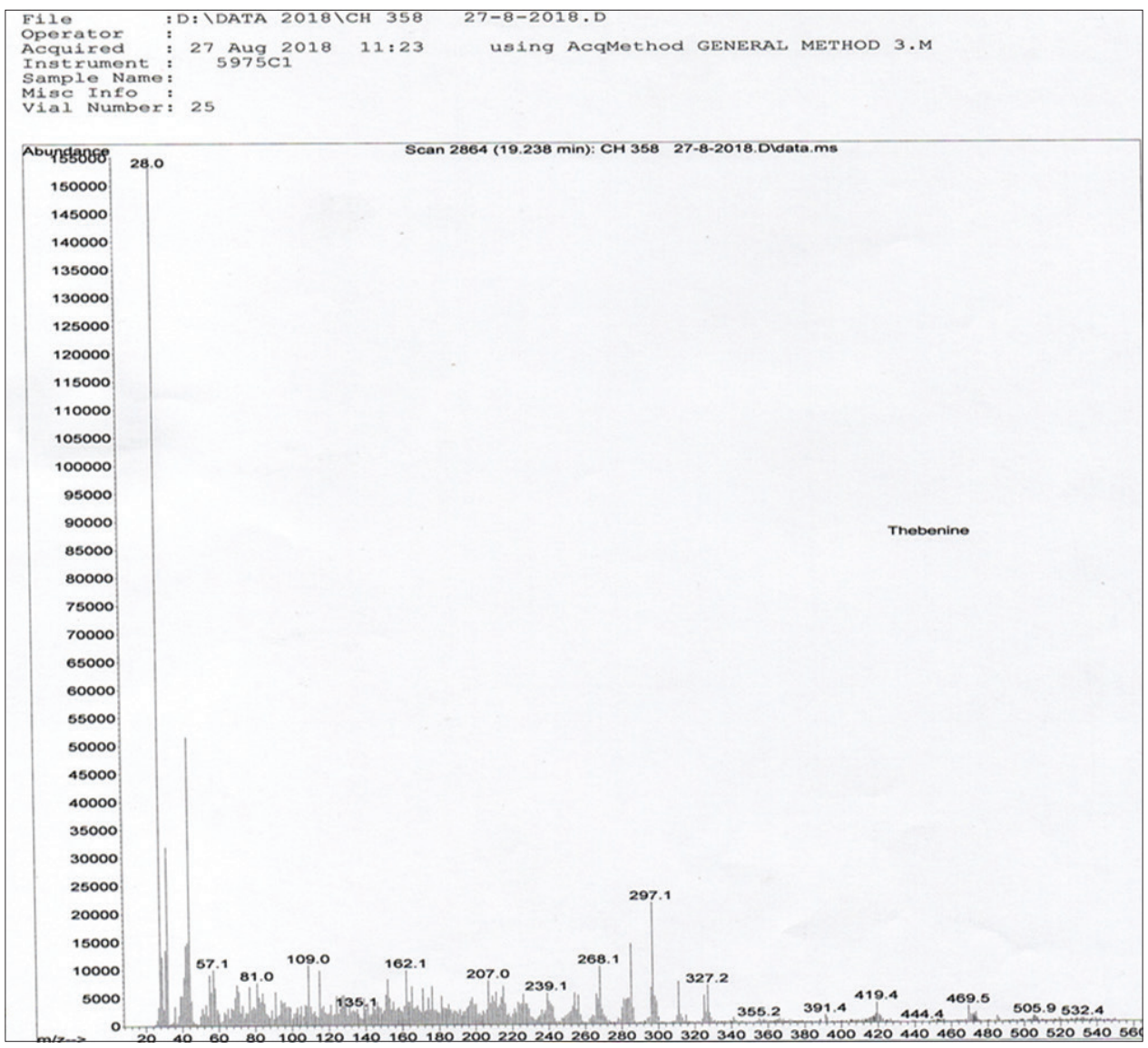

Figure 4C: Mass spectrum for thebenine 
preliminary testing tool for this reason. As they are relatively easy to perform compared with other tests applied in this respect, color tests are widely used by law enforcement agencies as initial testing when such agencies encounter a suspected drug. Figure 1 shows the narcotic substances images under optical microscope. ${ }^{[27]}$

\section{By HPLC-UV system}

To obtain pure material narcotic substances (detection) by reversed-phase HPLC with UV detection at $275 \mathrm{~nm}$, a flow rate of $1 \mathrm{ml} / \mathrm{min}$ was used and the injection volume is $100 \mu \mathrm{l}$, pre-fractionated the sample on a C18 solid phase column was used for quantification of narcotic substances at a constant temperature $\left(25^{\circ} \mathrm{C}\right)$ using an elution gradient with methanol: ethanol:acetonitrile $(1: 1: 1) \mathrm{V} / \mathrm{V} / \mathrm{V}$, retention information about the throat-irritating principal HPLC method allowed to determine thereof. ${ }^{[28]}$ A new HPLC gradient was, thus, developed, and only three well-resolved peaks were throat-irritating, shown in Figure 3.

\section{By GC-mass spectrum}

In general, studies demonstrate that all narcotics can be analyzed more precisely by applying the GC-MS technique. The reaction conditions may have to response to the morphine, codeine, and thebeinine that are shown in Figure 4. The

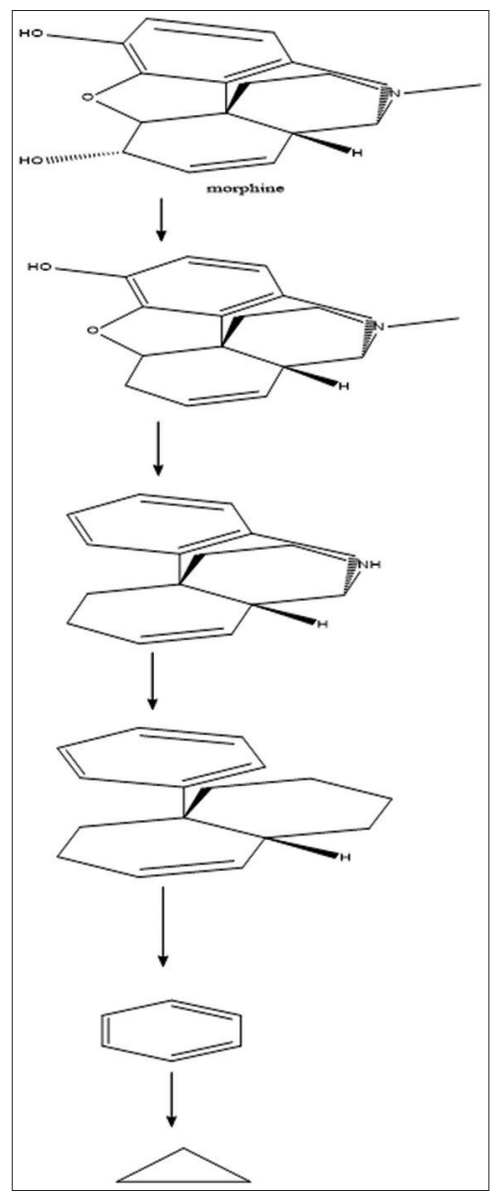

Scheme 1: The suggested mechanism of fragments pattern of morphine fragments allow for easy identification by mass spectrum. To shorten the overall GC analysis time of these compounds, a short, narrow bore column such as the $30 \mathrm{~mm} \times 0.250 \mu \mathrm{m}$ I.D. $\times 0.25 \mu \mathrm{m}, \mathrm{SS}$., Inlet He is recommended. Figures $4 \mathrm{a}-4 \mathrm{c}$ show the mass spectra degradation of narcotics substances morphine, codeine and thebenine, respectively and Schemes 1-3 show the mechanism of degradation of morphine, codeine and thebenine, respectively. The optimum conditions for mass spectra are summarized in Table 2.

Morphine [Table 3] undergoes a complex reordering process. It was reasonable to assume that the behavior of morphine molecules under the influence of the electron was more interesting. The mass spectrometer of morphine shows several peaks due to fragmentation of the mass into a charged mass of morphine, Figure 4a and Scheme 1 illustrate the proposed mechanism for the pattern of morphine fragments. The total spectra of morphine were recorded at $70 \mathrm{~V}$ which provided additional support for the proposed structural structure. The first electron was removed from morphine under the influence of electron bombardment, so it is likely to originate from the nitrogen atom to form the first molecular ion peak at $[\mathrm{M}-1]^{+} 285.1$ to give $\left[\mathrm{C}_{17} \mathrm{H}_{18} \mathrm{NO}_{2}\right]^{+}$ion. The morphine spectra of the morphine show a mean height peak due to the morphine-free $\mathrm{OH}$ group identified at $\mathrm{m} / \mathrm{z}$ at $266.1\left[\mathrm{C}_{17} \mathrm{H}_{17} \mathrm{NO}\right]^{+}$ion. The circulatory quaternary morphine

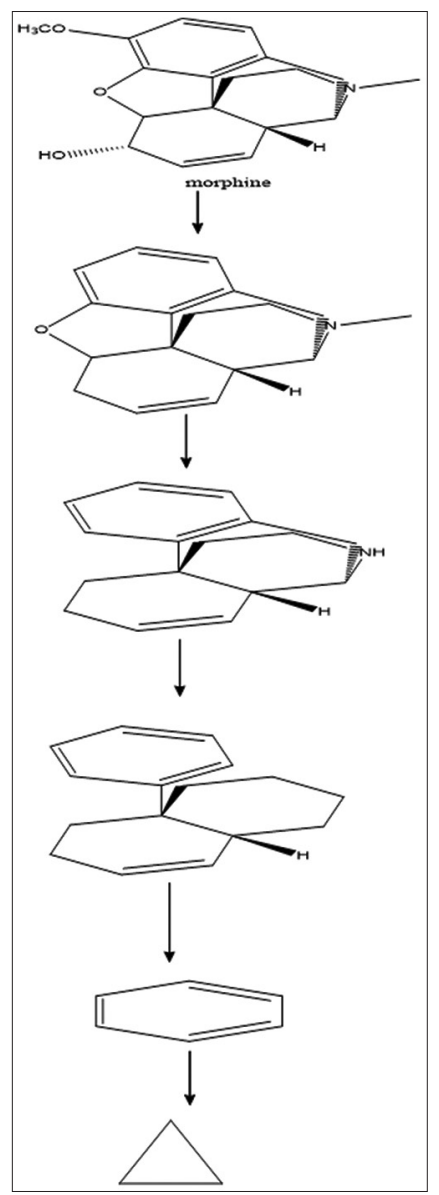

Scheme 2: The suggested mechanism of fragments pattern of codeine 
Parameters

Description Column

System Suitability Requirement

Isocratic Mobil phase

Test sample

Detection System

Maximum Wavelength

Flow Rate

Temperature

Pressure Background

Retention Time

Run Time

Injection Volume

\section{Conditions}

Ion Pac Ercus C18 RP-Column; $5 \mu \mathrm{m},(250 \times 4.6 \mathrm{~mm}$ id) (P/N $11051194 \mathrm{~L})$

USP Tailing Factor @ 10\% From average Peaks Height 1.1 Plates/Column $\geq 2010.80$

Methanol: Ethanol : acetonitrile (1:1:1) V/V/V

Narcotic substances diluted in the mobile phase

UV-Vis detection

$275 \mathrm{~nm}$

$1.2 \mathrm{~mL} / \mathrm{min}$.

At room temperature

80-90 Bar

$10 \mathrm{~min}$

$11 \mathrm{~min}$

$100 \mu \mathrm{L}$

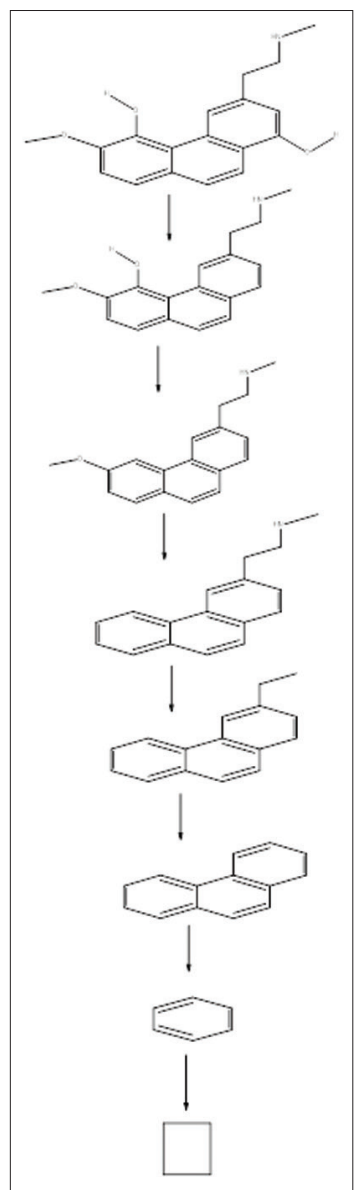

Scheme 3: The suggested mechanism of fragments pattern of thebenine

system $\left[\mathrm{C}_{16} \mathrm{H}_{13} \mathrm{NO}\right]^{+}$low peak is shown at $242.1 \mathrm{~m} / \mathrm{z}$. The cyclohexane morphine system is very complex since there must be several breaks before fragmentation is possible. The part of the cone morphine (titra) $\mathrm{m} / \mathrm{z} 215.1\left[\mathrm{C}_{16} \mathrm{H}_{13} \mathrm{~N}\right]^{+}$in which the ether ring does not exist, is subjected to a more fragmented process. After ethyl amine was liberated, the cyclic triple system $\left[\mathrm{C}_{14} \mathrm{H}_{8}\right]^{+}$is formed $[\mathrm{m} / \mathrm{z}=181]$. The other peaks at $\mathrm{m} / \mathrm{z}=70$ and 42.1 can be attributed to $\left[\mathrm{C}_{6} \mathrm{H}_{3}\right]^{+}$and $\left[\mathrm{C}_{3} \mathrm{H}_{6}\right]^{+}$, respectively.

The mass spectrum of the codeine [Table 4] shows several peaks due to the fragmentation of mass-to-charge of this compound, Figure $4 \mathrm{~b}$ and Scheme 2 show the suggested mechanism of fragments pattern of the codeine. The mass spectrum of the codeine shows a peak at $\mathrm{m} / \mathrm{z} 299.1$ which corresponding to molecular ion $\left[\mathrm{C}_{18} \mathrm{H}_{21} \mathrm{NO}_{3}\right]^{+}$. A peak at $\mathrm{m} / \mathrm{z}$ 270.1 was also observed which correspond to $\left[\mathrm{C}_{17} \mathrm{H}_{18} \mathrm{NO}_{2}\right]^{+}$ ion, attributed to the loss of methoxy group from molecular ion $\left[\mathrm{C}_{18} \mathrm{H}_{21} \mathrm{NO}_{3}\right]^{+}$ion. The peak at $\mathrm{m} / \mathrm{z} 229.1$ is due to the pentacyclic codeine fragment $\left[\mathrm{C}_{16} \mathrm{H}_{13} \mathrm{NO}\right]^{+}$. The fragment at $\mathrm{m} / \mathrm{z} 215.1$ can be attributed to tetracyclic codeine fragment $\left[\mathrm{C}_{16} \mathrm{H}_{13} \mathrm{~N}\right]^{+}$after losing ether ring. The fragment with $\mathrm{m} / \mathrm{z} 188.1$ attributed to tricyclic codeine fragment after losing ethylamine $\left[\mathrm{C}_{14} \mathrm{H}_{8}\right]$. The other peaks at $\mathrm{m} / \mathrm{z} 70.1$ and 42.1 can be attributed to $\left[\mathrm{C}_{6} \mathrm{H}_{3}\right]^{+}$and $\left[\mathrm{C}_{3} \mathrm{H}_{6}\right]^{+}$ions, respectively.

The mass spectrum of the thebenine [Table 5] shows several peaks due to the fragmentation of mass-to-charge of this compound, Figure 4c and Scheme 3 show the suggested mechanism of fragments pattern of the thebenine. The mass spectrum of the thebenine shows a peak at m/z 297.1 which corresponding to molecular ion $\left[\mathrm{C}_{18} \mathrm{H}_{19} \mathrm{NO}_{3}\right]^{+}$. A peak at $\mathrm{m} / \mathrm{z}$ 285.1 was also observed which correspond to $\left[\mathrm{C}_{17} \mathrm{H}_{18} \mathrm{NO}_{2}\right]^{+}$ ion, attributed to the loss of one hydroxyl group from molecular ion. The peak at $\mathrm{m} / \mathrm{z} 268.1$ is due to the fragment $\left[\mathrm{C}_{18} \mathrm{H}_{17} \mathrm{NO}\right]^{+}$ after losing the second hydroxyl group. The fragment at $\mathrm{m} / \mathrm{z}$ 239.1 can be attributed to thebenine fragment $\left[\mathrm{C}_{17} \mathrm{H}_{14} \mathrm{~N}\right]^{+}$ after losing methoxy group. The fragment with $\mathrm{m} / \mathrm{z} 207.1$ attributed to fragment $\left[\mathrm{C}_{16} \mathrm{H}_{10}\right]$ after losing methylamine. The peak at 162.1 can be attributed to the tricyclic aromatic 


\begin{tabular}{lc}
$\begin{array}{l}\text { Table 2: Data analysis parameters for separation and specific determination of Narcotic substances in GC-Mass } \\
\text { spectrum }\end{array}$ & $\begin{array}{c}\text { HP-5MS, 5\% Phenyl methyl Sillox (1629.5), } \\
\text { Column }\end{array}$ \\
\hline EMV mode & Gain Factor (1.00),70eV \\
Resulting EM Voltage & 1306 \\
Low Mass & 25.0 \\
High Mass & 550 \\
Threshold & 150 \\
Minimum Quality for all Narcotics & $\%(97-90)$ \\
Flow Rate & $\mathrm{ml} / \mathrm{min} 1.2$ \\
Run time & $0.921 \mathrm{~min} 17$ \\
Hold up Time & $1.3588 \mathrm{~min}$ \\
Solvent Delay & $1.5 \mathrm{~min}$ \\
Average velocity & $36.796 \mathrm{~cm} / \mathrm{sec}$ \\
Temperature & $8.81 \mathrm{Psi}$ \\
Pressure & Initial $70^{\circ} \mathrm{C}$ to Maximum $375^{\circ} \mathrm{C}$ \\
\hline
\end{tabular}

Table 3: Parameters table of Specific GC-Mass Spectrum for Morphine

\begin{tabular}{lc} 
Name & Morphine \\
\hline Cas Number & $000057-27-2$ \\
Entry number & 13 \\
Molecular Formula & $\mathrm{C}_{17} \mathrm{H}_{19} \mathrm{NO}_{3}$ \\
Misc information & Alkaloids sample; drugs \\
Match Quality & 99 \\
Company ID & $\mathrm{HP}$ \\
Retention Index & 0 \\
Melting Point & 197 \\
Boiling Point & - \\
Molecular Weight & $285.34 \mathrm{~g} / \mathrm{mol}$ \\
\hline
\end{tabular}

\section{Table 5: Parameters table of Specific GC-Mass} Spectrum for Thebenine

\begin{tabular}{lc} 
Name & Thebenine \\
\hline Cas Number & $000115-37-7$ \\
Entry Number & 144974 \\
Molecular Formula & $\mathrm{C}_{19} \mathrm{H}_{21} \mathrm{NO}_{3}$ \\
Misc information & NIST MS\#250620, Seq\# M179803 \\
Match Quality & 99 \\
Company ID & $\mathrm{NIST} 2008$ \\
Retention Index & 0 \\
Melting Point & - \\
Boiling Point & $203^{\circ} \mathrm{C}$ \\
Molecular Weight & $(327.2-311.15) \mathrm{g} / \mathrm{mol}$ \\
\hline
\end{tabular}

rings $\left[\mathrm{C}_{14} \mathrm{H}_{4}\right]^{+}$. The other peaks at $\mathrm{m} / \mathrm{z} 81.1$ and 57.1 can be attributed to $\left[\mathrm{C}_{6} \mathrm{H}_{5}\right]^{+}$and $\left[\mathrm{C}_{4} \mathrm{H}_{8}\right]^{+}$ions, respectively.

\section{Table 4: Parameters table of Specific GC-Mass} Spectrum for Codeine

\begin{tabular}{lc} 
Name & Codeine \\
\hline Cas Number & $000076-57-3$ \\
Entry Number & 12 \\
Molecular Formula & $\mathrm{C}_{18} \mathrm{H}_{21} \mathrm{NO}_{3}$
\end{tabular}

Misc information

Match Quality

Company ID

Retention Index

Melting Point

Alkaloids sample; drugs

99

$\mathrm{HP}$

0

155.00

Boiling Point

$203^{\circ} \mathrm{C}$

Molecular Weight

$299.14 \mathrm{~g} / \mathrm{mol}$

\section{CONCLUSION}

This work is described by three important analytical methods. The first method included a preliminary qualitative examination to determine whetherthe substance to be evaluated is narcotic or not and is performed using color reagents that are mixed with the narcotic substances and are examined under the optical microscope so, thus determine the category and type of narcotic. This process is compared to the images shown under the microscope with images previously taken to narcotic substances Standard. Either the second analytical method was completed using an ion chromatography IC method that separate three active components in mixture narcotic substances using presumptive color test before separation compounds using C18 column $4.6 \times 250 \mathrm{~mm}$, $5 \mu \mathrm{m}$ and mixture eluent methanol:ethanol:acetonitrile (1:1:1) as the mobile phase. This method can be used for the quality control at narcotic compounds. It is superior to the IC method 
that measures only three purported active components with spirited method that requires low separation times and have sufficient and very clearly peaks. The third method, the most important of the two previous analytical methods, the work in the GC-Mas method gives clear results and determines the substance category accurately, depending on the specific molecular ion of each material and the number of fragments, thus calculating the total mass of each compound.

Three methods that have been worked out are modern and easy methods that give excellent results on the identification of the narcotic substance category with very high accuracy.

\section{ACKNOWLEDGMENTS}

The author is heartily thankful to all staff who spent a great deal of efforts to accomplish this research in propitiate manner to be published in the journal. Authors would mention that this work was supported by Basrah Police Directorate/ Criminal Evidence labs and in collaboration with Pharmacy College and Science College/Basrah University.

\section{REFERENCES}

1. Al-Salman HN, Jasim KQ. Analytical methods for diagnosis a mixture of narcotic substances in seized materials. Int J Green Pharm 2018;12:216-26.

2. Samanidou VF, Hapeshi EA, Papadoyannis IN. Rapid and sensitive high-performance liquid chromatographic determination of four cephalosporin antibiotics in pharmaceuticals and body fluids. J Chromatogr B Analyt Technol Biomed Life Sci 2003;788:147-58.

3. FDA News Release: FDA Announces Safety Labeling Changes and Post-Market Study Requirements for Extended-Release and Long-acting Opioid Analgesics; 2013.

4. Nuckols TK, Anderson L, Popescu I, Diamant AL, Doyle B, Di Capua P, et al. Opioid prescribing: A systematic review and critical appraisal of guidelines for chronic pain. Ann Intern Med 2014;160:38-47.

5. Alavijeh MS, Chishty M, Qaiser MZ, Palmer AM. Drug metabolism and pharmacokinetics, the blood-brain barrier, and central nervous system drug discovery. NeuroRx 2005;2:554-71.

6. Anderson SM, Pierce RC. Emerging targets and therapeutics in the treatment of psychostimulant abuse. J Pharm Ther 2005;89:106.

7. Al-Salman HN. Analysis methods and qualitative diagnosis chromatographic for mixture of narcotic substances in seized materials. Eur J Sci Res 2017;147:403-11.

8. Matyus M, Kocsis G, Boldis O, Karvaly G, Magyar E, Fürész J, Gachályi A. Determination ofmorphine and codeine in serum after poppy seed consumptionusing gas chromatography-mass spectrometry. Acta Chromatogr
2012;24:351-65.

9. Rodríguez J, Castañeda G, Contento AM, Muñoz L. Direct and fast determination of paclitaxel, morphine and codeine in urine by micellar electrokinetic chromatography. J Chromatogr A 2012;1231:66-72.

10. Kovatsi L, Rentifis K, Giannakis D, Njau S, Samanidou V. Disposable pipette extraction for gas chromatographic determination of codeine, morphine, and 6-monoacetylmorphine in vitreous humor. J Sep Sci 2011;34:1716-21.

11. Furlan AD, Reardon $\mathrm{R}$, Weppler $\mathrm{C}$, National Opioid Use Guideline Group. Opioids for chronic noncancer pain: A new Canadian practice guideline. CMAJ 2010;182:923-30.

12. Kumar JV, Ramachandran D, Sushma K, Vijay S. Visible spectrophotometric methods for estimation of montelukast sodium in bulk dosage forms and formulations. Orient J Chem 2010;26:293-6.

13. Prabahar AE, Rao NR, Rao KR, Kumar PV. Method development and validation for the HPLC potency assay of prasugrel tablets. J Pharm Res 2011;4:980-2.

14. Bashir L, Shoaib MH, Naz S, Yousuf RI, Jabeen S, Israr F, et al. Development and validation of HPLC method for the determination of cefpodoxime proxetil in human plasma. Pak J Pharm Sci 2017;30:1603-7.

15. Patel NS, Tandel FB, Patel YD, Thakkar KB. Development and validation of stability-indicating HPLC method for simultaneous estimation of cefixime and linezolid. Indian J Pharm Sci 2014;76:535-40.

16. Maheshwari ML, Memon AA, Memon S, Memon FU, Mughal UU, Dayo A, et al. Optimization of HPLC method for determination of cefixime using 2-thiophenecarboxaldehyde as derivatizing reagent: A new approach. Saudi Pharm J 2015;23:444-52.

17. Bressolle F, Bromet-Petit M, Audran M. Validation of liquid chromatographic and gas chromatographic methods. Applications to pharmacokinetics. J Chromatogr B Biomed Appl 1996;686:3-10.

18. Diós P, Nagy S, Pál S, Pernecker T, Kocsis B, Budán F, et al. Preformulation studies and optimization of sodium alginate based floating drug delivery system for eradication of helicobacter pylori. Eur J Pharm Biopharm 2015;96:196-206.

19. Bogusz MJ. Handbook of Analytical Separations. Oxford: Elsevier Science; 2000. p. 1-567.

20. Zima J, Svancara I, Barek J, Vytras K. Recent advances in electroanalysis of organic compounds at carbon paste electrodes. Crit Rev Anal Chem 2009;39:204-27.

21. Mujtaba A, Kohli K. In vitro/in vivo evaluation of HPMC/alginate based extended-release matrix tablets of cefpodoxime proxetil. Int JBiol Macromol 2016;89:434-41.

22. Malenka RC, Nestler EJ, Hyman SE. Chapter 15: Reinforcement and addictive disorders. In: Sydor A, Brown RY, editors. Molecular Neuropharmacology: A Foundation for Clinical Neuroscience. $2^{\text {nd }}$ ed. New York: McGraw-Hill Medical; 2009. p. 375.

23. Stahl SM. Amphetamine DL. In: Prescriber's Guide: 
Stahl's Essential Psychopharmacology. $6^{\text {th }} \mathrm{ed}$. Cambridge, United Kingdom: Cambridge University Press; 2017. p. 45-51.

24. Qi H, Li S. Dose-response meta-analysis on coffee, tea and caffeine consumption with risk of Parkinson's disease. Geriatr Gerontol Int 2014;14:430-9.

25. American College of Obstetricians and Gynecologists. ACOG committee opinion no 462: Moderate caffeine consumption during pregnancy. Obstet Gynecol 2010;116:467-8.

26. Ghode PD, Pawar SP. Stability indicating HPLC method development and validation for the simultaneous determination of cefpodoxime proxetil and ofloxacin in its dosage forms. Int J Pharm Bio Sci 2015;6:183-93.

27. Karanjia J. Development and validation of chemometric assisted spectrophotometric technique for simultaneous estimation of cinitapride and pantoprazole from bulk and combined dosage form. Int J Pharm Sci Drug Res 2015;7:198-204.

28. Al-Salman HN, Hussein HH, Al-Nuaim M. Quantitative analysis of cephradine using the modern highperformance liquid chromatographic method. Asian J Pharm 2018;12:228-34.

29. Alaa G, AL-Salman HN, Shaker AN. GC-mass analysis and estimation of pomegranate husks extracts and the biological efficacy of compound tri-butyl acetyl citrate as one of the extract against food fungi. Orient J Chem 2018;34:2089-97.

\section{PAGES OF SUPPLEMENTARY MATERIAL}

\section{Description of Morphine}

Morphine, the most important alkaloid of opium, is classified pharmacologically as a narcotic analgesic. Morphine sulfate, USP (pentahydrate), is chemically designated 7 , 8-didehydro-4, 5 $\alpha$-epoxy-17-methylmorphinan-3, $6 \alpha$-diol sulfate $(2: 1)$ (salt), pentahydrate, a white crystalline powder, soluble in water. It has the following structural formula:

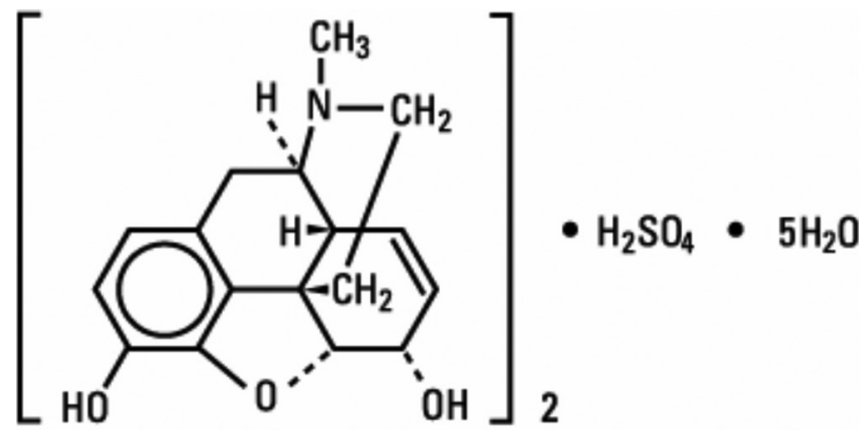

\section{Preservative-free}

Morphine sulfate injection, USP, is a sterile, nonpyrogenic solution of morphine sulfate in water for injection. This product was designed to be administered by the intravenous route with a compatible Hospira infusion device.
For $0.5 \mathrm{mg}$ or $1 \mathrm{mg}$ presentation, each $\mathrm{mL}$ contains morphine sulfate, USP (pentahydrate).

$0.5 \mathrm{mg}$ or $1 \mathrm{mg}$, respectively, and sodium chloride, USP, $9 \mathrm{mg}$ in water for injection, USP. May contain sodium hydroxide and/or hydrochloric acid for $\mathrm{pH}$ adjustments. For $5 \mathrm{mg}$ presentation, each $\mathrm{mL}$ contains morphine sulfate, USP (pentahydrate), $5 \mathrm{mg}$, sodium chloride, USP, $7.6 \mathrm{mg}$, with citric acid, USP, anhydrous $0.4 \mathrm{mg}$, and sodium citrate, USP, dihydrate $0.2 \mathrm{mg}$ added as buffers in water for injection, USP. May contain additional citric acid and/or sodium citrate for $\mathrm{pH}$ adjustment. The $\mathrm{pH}$ range for all preservative-free morphine sulfate injection, USP presentations is 2.5-6.5. Morphine Sulfate Injection, USP, contains no antioxidant, bacteriostatic or antimicrobial agent, and is intended only as a single-dose unit, to provide analgesia through the intravenous route, using a compatible Hospira infusion device. Each vial is intended for single use only. When the dosing requirement is completed, the unused portion should be discarded in an appropriate manner.

\section{Clinical pharmacology}

Morphine produces a wide spectrum of pharmacologic effects including analgesia, dysphoria, euphoria, somnolence, respiratory depression, diminished gastrointestinal motility, and physical dependence. Opiate analgesia involves at least three anatomical areas of the central nervous system: The periaqueductal-periventricular gray matter, the ventromedial medulla, and the spinal cord. A systemically administered opiate may produce analgesia by acting at any, all, or some combination of these distinct regions. Morphine interacts predominantly with the $\mu$-receptor. The $\mu$-binding sites

of opioids are very discretely distributed in the human brain, with high densities of sites found in the posterior amygdala, hypothalamus, thalamus, nucleus caudatus, putamen, and certain cortical areas. They are also found on the terminal axons of primary afferents within laminae I and II (substantia gelatinosa) of the spinal cord and in the spinal nucleus of the trigeminal nerve.

\section{Class: Analgesic, opioid}

Indications: Relief of moderate-to-severe acute and chronic pain; relief of pain of myocardial infarction; relief of dyspnea of acute left ventricular failure and pulmonary edema; and preanesthetic medication.

\section{Infumorph}

Used in continuous microinfusion devices for intrathecal or epidural administration in the treatment of intractable chronic pain.

\section{Extended release products}

Moderate-to-severe pain when continuous, around-the-clock opioid analgesia is needed for an extended period of time. 


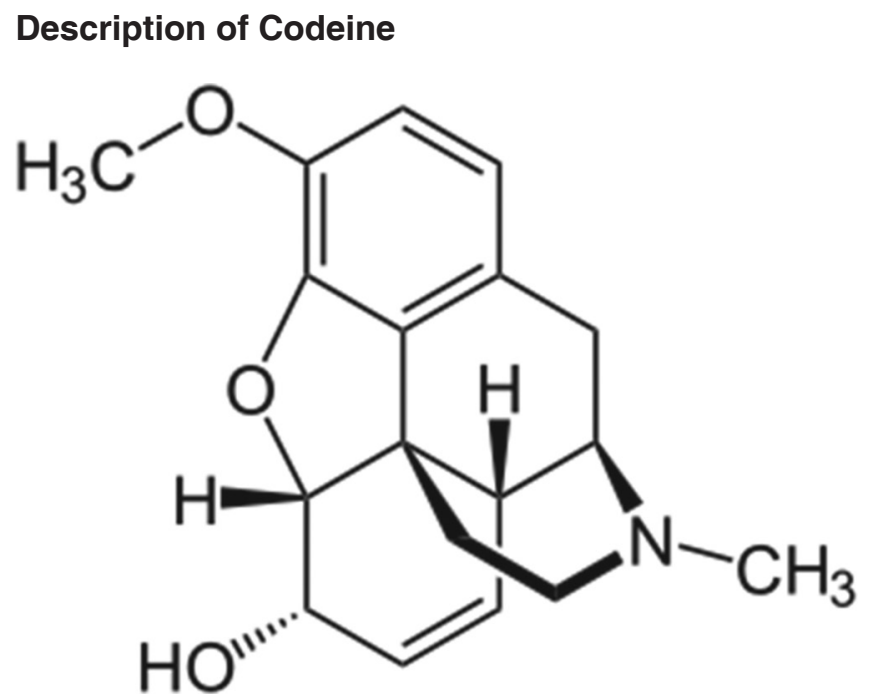

Codeine is used to treat mild and moderate pain and to relieve cough. Codeine is also used to treat diarrhea and diarrhea caused by irritable bowel syndrome. Although loperamide (which is available as an over-the-counter medication for diarrhea), diphenoxylate, paregoric or even opium tincture (also known as Tincture of Opium) is a drug that is frequently used to treat severe diarrhea. ${ }^{[3]}$ CODIN is effective in reducing pain associated with cancer.

\section{Compositions}

Codine is marketed as a single formulation or in combination with other drugs such as paracetamol (e.g., Cocodamol, Paracod, Panadeine, and Tylenol) with a codeine chain, including Tylenol (1, 2, 3, and 4) and Aspirin, or ibuprofen (as in Nurofen Plus), and these groups have greater pain relief when compared to any of the drugs (have an added effect), and codeine is commonly marketed in products containing codeine with other people or muscle relaxants, as well as codeine with phenacetin (Emprazil with codes 1, 2, 3, 4, and 5), nadethacin, diclofenac, and others, as well as more complex mixtures, including aspirin + paracetamol + codeine, caffeine, antihistamines, and other substances, such as those mentioned above.

\section{Description of Thebenine}

Thebaine (paramorphine), also known as codeine methyl enol ether, is an opiate alkaloid, its name coming from the Greek $\Theta \tilde{\eta} \beta \alpha 1$, Thēbai (Thebes), an ancient city in Upper Egypt. A minor constituent of opium, thebaine is

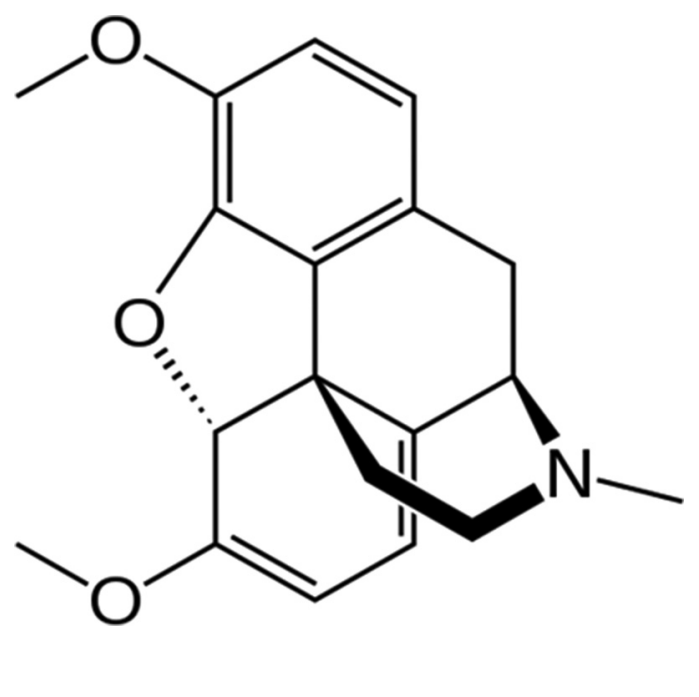

chemically similar to both morphine and codeine but has stimulatory rather than depressant effects. At high doses, it causes convulsions similar to strychnine poisoning. The synthetic enantiomer (+)-thebaine does show analgesic effects apparently mediated through opioid receptors, unlike the inactive natural enantiomer (-)-thebaine while thebaine is not used therapeutically, it is the main alkaloid extracted from Papaver bracteatum (Iranian poppy) and can be converted industrially into a variety of compounds, including oxycodone, oxymorphone, nalbuphine, naloxone, naltrexone, buprenorphine, and etorphine. Butorphanol can also be derived from thebaine.

Thebaine is controlled under international law, is listed as a Class A drug under the Misuse of Drugs Act 1971 in the United Kingdom, is controlled as an analog of a Schedule II drug per the Analog Act in the United States, and is controlled with its derivatives and salts, as a Schedule I substance of the Controlled Drugs and Substances Act in Canada. The 2013 US Drug Enforcement Administration aggregate manufacturing quota for thebaine (ACSCN 9333) was unchanged from the previous year at 145 metric tons.

This alkaloid is biosynthetically related to salutaridine, oripavine, morphine, and reticuline.

In $2012,146,000 \mathrm{~kg}$ of thebaine were produced in 2013, Australia was the main producer of poppy straw rich in thebaine, followed by Spain and then France. Together, those three countries accounted for about $99 \%$ of the global production of such poppy straw. 